\title{
Frontopolar Artery
}

National Cancer Institute

\section{Source}

National Cancer Institute. Frontopolar Artery. NCI Thesaurus. Code C32640.

An artery arising from the A2 segment of the anterior cerebral artery that supplies the corpus callosum. 